\title{
Using open software to teach resource assessment of renewable energies
}

\author{
Ulazia, Alain ${ }^{c}$; Urresti, Aitor ${ }^{\text {b }}$ Antxustegi, M. Mirari ${ }^{a}$; Gonzalez Alriols, Maria ${ }^{a}$; \\ Campos-Celador, Alvaro ${ }^{\text {; }}$ Ibarra-Berastegi, Gabriel ${ }^{\text {c,e }}$; Garcia Arribas, Raul ${ }^{c, d}$. \\ ${ }^{a}$ Departament of Chemical Engineering and Environment, University of Basque Country. \\ ${ }^{b}$ Department of Thermal Machines and Engines, University of Basque Country. \\ ${ }^{c}$ Department of Nuclear Engineering and Fluid Mechanics, University of Basque Country. \\ ${ }^{\mathrm{d}}$ Confederación Hidrografica Cantábrico. ${ }^{\mathrm{e}}$ Plentzia Itsas Estazioa (PIE). Joint research Unit \\ UPV/IOE. University of the Basque Country.
}

\begin{abstract}
The students of the Faculties of Engineering of the Universitty of Basque Country (Gipuzkoa-Eibar and Bilbao) in the last years of their studies, before becoming engineers, have the opportunity to select a block of subjects intended to enhance their knowledge on Wind Energy, Ocean Energy, Bioenergy and Hydraulic Energy. These subjects are devoted to different aspects of the water cycle management, and geographical representations of wind, ocean and Bioenergy energy resource. Apart from the transmission of good practices, the focus is practical and is based on hands-on computer real-life exercises, which involves not only intensive programming using high-level software, but also the spatial representation of results. To that purpose three main open source codes are used: EPANET (https://www.epa.gov/water-research/epanet), QGIS (https://www.qgis.org/) and $R$ (https://www.cran.r-project.org/). Students learn how to address reallife problems regarding the correct calculation of water distribution networks with EPANET, geographical representation of wind and ocean energy resource with $R$, and spatial representation of Bioenergy resource with QGIS.
\end{abstract}

Keywords: QGIS; R; EPANET; learning by problems. 


\section{Introduction}

During the last two years, students at Gipuzkoa-Eibar Faculty of Engineering in the Grade of Engineering for Renewable Energies (4 years) have many specialization subjects (http://www.ehu.eus/es/web/eibar). We will expose "Bioenergy" (second year), "Wind Energy" (third year), "Hydraulic Energy" (third year, in collaboration with the Faculty of Engineering of Bilbao) and "Ocean Energy" (fourth year), because of their interest in terms of the use of open software for the analysis of renewable energy resource and its geographical and spatial distribution. We must underline that the surveys of the students about the four subjects are generally outstanding.

- Bioenergy: teachers use learning by problems and learning by projects techniques during all the year (the evaluation is fully based on cooperative works on these projects). The software for geographical information systems QGIS is a powerful instrument for the analysis of biomass resource in specific regions taking into account even relevant variables for the extraction of wood.

- Wind Energy: $30 \%$ of the subject is taught by learning by problems techniques in which the software $\mathrm{R}$ for statistical computation is a basic tool. It not only allows statistical calculation of wind energy production for certain turbines at specific locations, it also allows the geographical representation of wind energy.

- Hydraulic Energy: $30 \%$ of this subject is also practical and based on learning by problems. Here the software EPANET is used in connection with $\mathrm{R}$ to study network of fluids, and management and maintenance of hydraulic systems. So the focus is practical with hand-on-exercises and all the teaching activities are closely interconnected with hydraulic systems and the maintenance of hydraulic energy plants.

- Ocean Energy: $50 \%$ of the subject is practical based on learning by problems with $R$. Seven problems of two weeks are designed to solve along the 15 weeks of the subject about the wave, thermal gradient and stream energy potential of the sea in chosen areas of the world. We use satellite and mesoscale model data for that, and all the process is developed by step-by-step spatial representations of energy potential and bathymetric characteristics of the sea via $\mathrm{R}$.

This includes handling two groups of skills:

1. Solving real-life problems like the correct design of water supply tanks, overall planning for a given area and water, wind, wave or biomass availability estimation under several scenarios This involves the use of a high-level programming software like EPANET (https://www.epa.gov/water-research/epanet) and R (https://www.cran.r-project.org/). . 
2. Spatial planning and geographical characterization of available energy resources. This implies the use of geographical information system (GIS) software and R, due to its modular nature holds the full functionality of any GIS software.

\section{Method}

When students select our subjects in their third and fourth year of studies they have a reasonable degree of computing programming skills and they are already somehow familiar with general purpose software like VisualBasic, Fortran or $\mathrm{C}++$. Due to this initial background, it is possible for the team of teachers to design classes as a set of practical exercises within a bigger resource analysis project. The software we use in classes are EPANET, R and QGIS.

\subsection{EPANET}

EPANET is an open source code intended to model water distribution piping systems. EPANET is public domain software that may be freely copied and distributed. It is a Windows 95/98/NT/XP program, which can be installed without problems by the students in their own computers in order to work also at home. EPANET performs extended period simulation of the water movement and quality behaviour within pressurized pipe networks. EPANET's Windows user interface provides a visual network editor that simplifies the process of building piping network models and editing their properties and data. EPANET provides an integrated computer environment for editing input data. Various data reporting and visualization tools are used to assist in interpreting the results of a network analysis (https://www.epa.gov/water-research/epanet). It is worthwhile to mention that EPANET has made simple solving the type of non-linear equations involved. Before EPANET and similar tools this had to be solved using the Hardy-Cross method with successive approaches after a set of initial estimations of the unknowns.

\section{2. $R$}

$\mathrm{R}$ is freely available software that has turned out to be a perfect scientific tool due to its modular nature and its data processing capabilities. The reason for this is that $\mathrm{R}$ has a core module that can easily interact with an increasing number of packages, specifically developed by a growing amount of scientific communities that allow taking advantage of previous research. Due to the high potential of $\mathrm{R}$, students feel that by incorporating $\mathrm{R}$ into their syllabus, they have gained access to a cutting edge, powerful and valuable tool that will make a difference in their professional career.

Additionally, R, apart from being free software, is continuously being developed with never ending improvements in the form of new packages that are adopted by an increasing 
number of scientific communities. After students have learned how to use it, they will become members of this huge community. Additionally, all the information on maps representation, bathymetry, wind data, wind rose representation, water management and associated spatial planning, is usually freely available and made public by regional, national and European institutions using Geographical Information Systems (GIS) standards, usually shp files. For this reason, students need to effectively read this information, calculate results and finally, yield a spatial representation of the same. Packages like "sp" "rgeos", "rgdal", "maps", "maptools" and "mapdata" have been developed to make R work with full functionalities just like any GIS software, while exhibiting all the capabilities of any highlevel programming software.

\subsection{QGIS}

QGIS is an official project of the Open Source Geospatial Foundation (OSGeo). QGIS provides a continuously growing number of capabilities provided by core functions and plugins. You can visualize, manage, edit, analyse data, and compose printable maps. Get a first impression with a more detailed feature list. This specific software for geographic information systems (GIS) purposes offers a more visual interface than R for geographical representation and spatial analysis. It can be a good complement of $\mathrm{R}$ to obtain a more understandable design in the presentation of maps, and to facilitate more visual operations than rough codes and scripts needed in $\mathrm{R}$.

\subsection{Learning by problems}

Using EPANET, R and QGIS to introduce concepts related to the subjects mentioned above, represents for our students a real and pragmatic way of problem solving. Taking into account Bloom's (1956) Taxonomy of Educational Objectives for Skills-Based Goals, they get a high level of expertise on 'guided response' and 'mechanism': 1) the student knows the steps required to complete the task, and 2) performs the tasks in a confident, proficient and habitual manner. The student simulates what the scientist do every day and use the logic of discovery instead of the logic of justification (Hanson, 1958). As Clement states (Clement 1988, 2008) in his deep study on scientific creativity, when dealing with a problem heuristically there is no difference between the problem solving capacity of an expert and of a student. That is, the students should know the real scientific practice, and not only the final important and supposedly finished theories (Chi et al., 1981, 1989). The state of the art in this domain has been developed very deeply in constructive problem solving via the use of analogy, visual thinking, spatial abstraction and other different heuristic instruments have been pointed out for that (Welsh 2012, Simons 1993, Newel 1972). We will show that the mentioned software is a powerful instrument to implement this heuristics understood as the art for solving problems. 


\section{Results: examples}

\subsection{EPANET-R for hydraulic resource analysis}

For example, students learn to read relevant information of water facilities from public institutions websites and at a second stage, they learn how to extract relevant information and put it on a map to represent, for example, river's catchment or flooding areas (Fig.1-2).

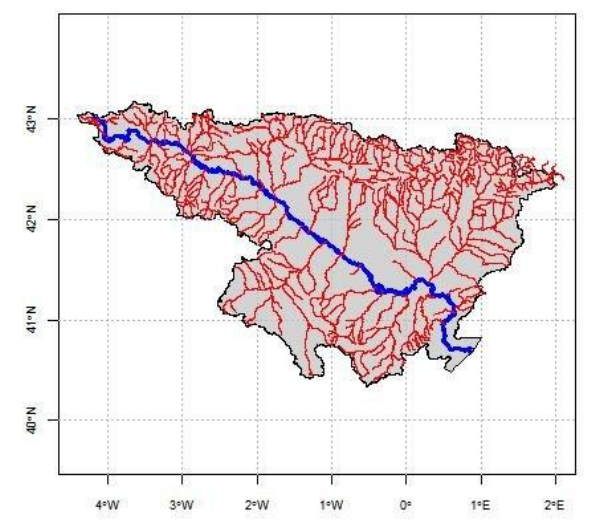

Fig. 1. Layout of Ebro river's catchment

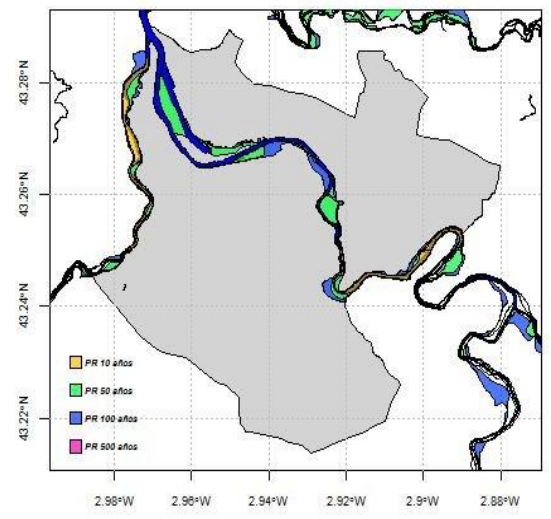

Fig. 2. Flooding areas in Bilbao city

The skills they get include the estimation of water availability in the frame of climate change scenarios as provided by the last AR5 report and associated CMP5 models projections. Students learn how to download CMIP5 data from: http://climexp.knmi.nl/selectdailyseries.cgi?someone@somewhere. Furthermore, visual thinking is trained heuristically by the interpretation of the relation between altitude isolines and the catchment of the valley around the river along the gradient.

\section{$3.2 R$ for wind and wave energy resource assessment}

Here students represent spatially the wind energy potential in terms of Capacity Factor of the offshore floating wind farm over the Iberian Mediterranean area. Or they represent the wave energy potential over the Bay of Biscay $(\mathrm{kW} / \mathrm{m})$ based on the TOPEX satellite data (see fig. 3) .

The skills they get include the estimation of energy resource and its spatial distribution, and the treatment of rough data coming from mesoscale models and satellites. Students learn 
how to download data of TOPEX from the NOOA (National Oceanic and Atmospheric Administration):

https://www.nodc.noaa.gov/woce/woce_v3/wocedata_2/sat_sl/topex/docs/topex_doc.htm
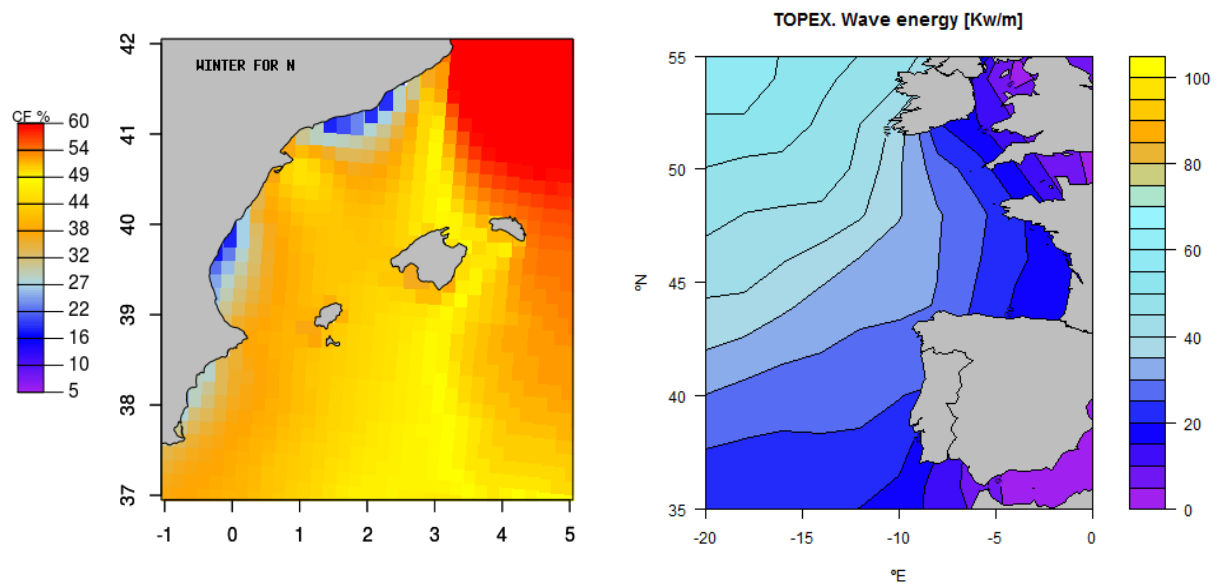

Fig. 3. Wind energy (Balearic Islands) and Wave Energy (Gulf of Biscay)

The heuristic of this kind of maps is important because implicitly these colour representations are huge numeric matrices constructed by several operational variables in the $\mathrm{R}$ algorithm developed during many class hours.

\subsection{QGIS for bioenergy resource}

In this case, the learning by problems project intends to quantify, locate and revalue the available forestry biomass as well as the forestry and wood waste for its subsequent thermal energy production. As expected, as they belong to two different types of biomass (forestry and industry residues), it would not be logical to apply a unified calculation methodology. Before knowing for sure the thermal energy that could be obtained from woody origin biomass, a free software program called QGIS will be used to find out the wooded area of the region (Figure 4). The restrictions of protected areas and nearness of roads are taken into account, together with the location of forest species, in order to calculate different biomass resource options over their intersections. 


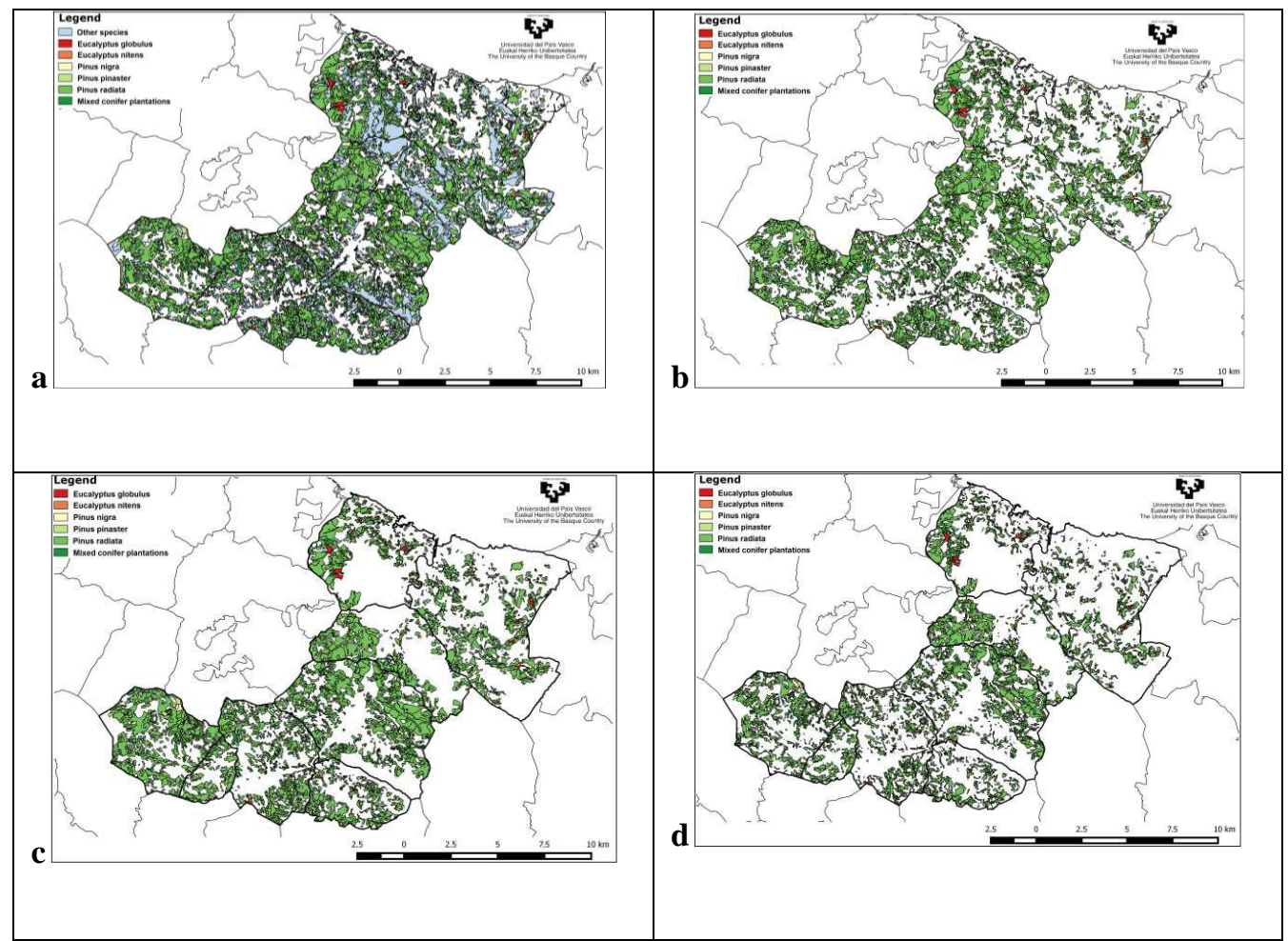

Fig. 4: QGIS generated maps: a) Location of all forest species in Debabarrena b) Spatial distribution of total bioenergy potential in Debabarrena c) Location of bioenergy without protected areas d) Location of bioenergy near roads and without protected areas

Heuristically speaking, the logical construction of the inner algorithm in order to superpose several geographical layers with different levels of priority in the forest establishes a creative hands-on activity for the visual representation, which is specified locally in each region and type of forest.

\section{Results in the classroom and conclusions}

We are applying these learning by problems techniques via free software in the Grade of Engineering for Renewable Energies for the last years -four years in some subjects. Taking into account that there are approximately 70 students per course we are speaking about more than 200 students, which have shown very good opinions in their surveys when they have been questioned about these subjects and the teaching methods used. For example, last year the teachers of Wind Energy and Ocean Energy obtained 4.5 out of 5.

The introduction of the mentioned software has enhanced our learning by problems perspective with respect to previous more theoretical and expositive way of teaching. We must also mention that this learning by problem techniques are being combined with more 
general learning by project activities especially in the subject of Bioenergy, in which the cooperative work between students is remarkable. Furthermore, in case of Hydraulic Energy one of the teachers (Raul Garcia) works in a near hydrographic confederation (Cantabria) and consequently teaches very practical problems related to real jobs. Hence, a suitable learning atmosphere is created in the two schools due to this cooperative background together with the use of free software for the study of renewable energies and hydrology that constitutes areas with great social implications and job opportunities.

\section{References}

Bloom, B. S. (1956). Taxonomy of Educational Objectives. New York: David McKay.

Clement, J. (1988). Observed methods for generating analogies in scientific problem solving. Cognitive Science, 12(4), 563-586.

Clement, J. (2008). Creative model construction in scientists and students: The role of imagery, analogy, and mental simulation. Springer Science \& Business Media.

Chi, M. T., Feltovich, P. J., \& Glaser, R. (1981). Categorization and representation of physics problems by experts and novices. Cognitive science, 5(2), 121-152.

Chi, M. T., Bassok, M., Lewis, M. W., Reimann, P., \& Glaser, R. (1989). Selfexplanations: How students study and use examples in learning to solve problems. Cognitive science, 13(2), 145-182.

Hanson, N. R. (1958). The logic of discovery. The Journal of Philosophy, 1073-1089.

Newell, A., \& Simon, H. A. (1972). Human problem solving (Vol. 104, No. 9). Englewood Cliffs, NJ: Prentice-Hall.

Simons, P. R. J. (1993). Constructive learning: The role of the learner. In Designing environments for constructive learning (pp. 291-313). Springer Berlin Heidelberg.

Welsh, T. M. (2012). Designing environments for constructive learning (Vol. 105). T. M. Duffy, J. Lowyck, \& D. H. Jonassen (Eds.). Springer Science \& Business Media. 